\title{
Airflow limitation and changes in pulmonary function among bleachery workers
}

\author{
A.J. Mehta*, P.K. Henneberger*, K. Torén ${ }^{\#}$ and A-C. Olin ${ }^{\#}$
}

ABSTRACT: This study investigated whether chronic airflow limitation and rapid decline in pulmonary function were associated with peak exposures to ozone and other irritant gases in pulp mills.

Bleachery workers potentially exposed to irritant gassings $(n=178)$ from three Swedish pulp mills, and a comparison group of workers not exposed to irritant gassings $(n=54)$ from two paper mills, were studied. Baseline surveys occurred in 1995-1996, with follow-up surveys in 1998-1999. Participants performed spirometry and answered questions regarding ozone, chlorine dioxide $\left(\mathrm{ClO}_{2}\right)$, and sulphur dioxide $\left(\mathrm{SO}_{2}\right)$ gassings.

From regression models controlling for potential confounders, declines in both the forced expiratory volume in one second $\left(F E V_{1}\right)\left(-24 \mathrm{~mL} \cdot \mathrm{yr}^{-1}\right)$ and the forced vital capacity (FVC) $\left(-19 \mathrm{~mL} \cdot \mathrm{yr}^{-1}\right)$ were associated with $\mathrm{ClO}_{2} / \mathrm{SO}_{2}$ gassings. At follow-up, the prevalence of chronic airflow limitation (i.e. FEV1/FVC less than the lower limit of normal) was elevated for participants with only pre-baseline ozone gassings and with both pre-baseline and interval ozone gassings, after controlling for potential confounders.

These findings suggest that obstructive effects among bleachery workers are associated with ozone gassings, and that adverse effects on spirometry might also accompany chlorine dioxide/ sulphur dioxide gassings. Peak exposures to irritant gases in pulp mills should be prevented.

KEYWORDS: Airways disease, ozone exposure, pulmonary function, pulp mill workers

$\mathbf{P}$ ulp mill workers, especially those involved in the bleaching process, have the potential for exposure to a variety of irritant gases that include sulphur dioxide $\left(\mathrm{SO}_{2}\right)$, chlorine $(\mathrm{Cl})$, and chlorine dioxide $\left(\mathrm{ClO}_{2}\right)$ [1]. Epidemiological studies have found that pulp mill workers with peak exposures to $\mathrm{Cl}$ and other irritant gases have an increased risk for reduced lung function [2-5]. Starting in the early 1990s, some Swedish pulp mills began replacing $\mathrm{Cl}$ and $\mathrm{ClO}_{2}$ with ozone as a bleaching agent [6]. Workers in these settings most likely experience low-level background exposure to ozone, as well as episodic high-level exposure due to accidental gassings.

Ozone is a known respiratory irritant, and shortterm exposure to ozone can cause increased airways responsiveness and inflammation [7]. Studies conducted in non-occupational settings provide mixed evidence that exposure to ozone can lead to decrements in lung function. Experimental chamber exposure studies with healthy human subjects have demonstrated that ozone-induced respiratory symptoms and decrements in lung function are a function of exposure concentration, minute ventilation during exposure, and duration of exposure, and that response to ozone decreases with age $[8,9]$. Epidemiological studies conducted in the USA revealed that the onset of asthma in nonsmoking adult males was associated with long-term ambient concentrations of ozone in air pollution $[10,11]$. In the initial cross-sectional survey of a community-based study, participants with elevated ambient exposures to photochemical oxidants were at greater risk for low lung function [12]. Investigators followed a subset of the same cohort over 8-10 yrs and found that an accelerated decline in lung function was associated with neither chronic ambient exposures to ozone nor an acute response to ozone in a laboratory setting [13].

The evidence for an ozone-lung function relationship is also mixed and is based on studies of pulp mill workers in Sweden that were conducted in the mid- and late-1990s. In a study at one Swedish pulp mill, investigators found increased exhaled nitric oxide among bleachery workers reporting ozone gassings, suggesting airways inflammation may have been present [14]. The investigators also reported that the forced expiratory volume in one second (FEV1) was lower for
AFFILIATIONS

*Division of Respiratory Disease Studies, National Institute for Occupational Safety and Health, Centers for Disease Control and Prevention, Morgantown WV, USA.

\#Sahlgrenska University Hospital, Goteborg, Sweden.

CORRESPONDENCE

P. Henneberger

Division of Respiratory Disease Studies

National Institute for Occupational

Safety and Health

1095 Willowdale Road

Morgantown

WV 26505

USA

Fax: 13042855820

E-mail: pkh0@cdc.gov

Received

June 122004

Accepted after revision:

March 172005

\section{SUPPORT STATEMENT}

This study was funded by CDCNIOSH, the Swedish Council for Worklife Research. 
bleachery workers compared with process workers from the adjacent paper mill $(97.6 \%$ versus $104.0 \%$ predicted; $\mathrm{p}=0.007)$, while there was no difference between the two groups in forced vital capacity (FVC) [14]. When comparisons were limited to the bleachery workers, those who reported ozone gassings did not have lower FEV1 or FVC. In a subsequent study, these data were combined with comparable data that had been gathered from workers at a second Swedish pulp and paper mill operation where ozone was used. The FEV1 was only marginally reduced for the bleachery workers compared with their paper-mill counterparts $(p=0.19)$ [15]. In another round of field studies conducted several years later, the sample size was increased by including workers from a third pulp mill that used ozone. The bleachery workers who reported at least four ozone gassings had a lower FEV1 than the comparison paper mill workers (99.9\% versus $105.3 \%$ pred), but this difference was not statistically significant $(p=0.17)$ [16].

The current authors sought to further explore the relationship between ozone exposure and lung function by conducting additional analyses of data from the three pulping operations in Sweden. In particular, longitudinal change in pulmonary function, which might be a more accurate indicator of the effect of gassings than the cross-sectional analyses that have been published, was examined. Also, it was investigated whether those who reported gassings were more likely to have chronic airflow limitation.

\section{MATERIALS AND METHODS}

The bleachery and paper mill workers identified for this study had participated in field studies conducted in the 1990s [1517]. During 1995-1996, researchers invited all process, maintenance, and laboratory workers in the bleaching departments $(n=240)$ from three sulphate pulp mills to participate in a medical survey $[15,17]$. Of those invited, $76 \%$ of the bleachery workers $(n=183)$ performed spirometry testing. Using the same methods at follow-up surveys during 1998-1999 [16], 179 bleachery workers repeated spirometry testing. One bleachery worker was excluded as an outlier for body weight, which left a total of 178 bleachery workers (74\%) in the exposed group whose data were included in the final analyses of the present study. Researchers established a comparison group by inviting process workers $(n=93)$ from two adjacent paper mills to participate in the 1995 and 1996 surveys [15]. Of those invited, 63 of the paper mill workers performed spirometry testing. At follow-up during 1998-1999 [16], 62 paper mill workers (67\%) repeated spirometry testing. Eight paper mill workers were excluded because they reported a history of gassings while working in pulp mills, which left a total of 54 paper mill workers (58\%) for final analysis in this study. More details about the study population are documented in previous articles [15-17].

\section{Exposure assessment}

$\mathrm{Cl}$ and/or $\mathrm{ClO}_{2}$ was used as a bleaching agent in each of the three pulp mills (Mills A, B, C) starting in the 1950s, but they were replaced with ozone in 1995 at Mill A, 1993 at Mill B and 1992 at Mill C. Workers were still exposed to other irritant gases after the introduction of ozone. $\mathrm{SO}_{2}$ is still used in one of the pulping operations in Mill A. Production of hypochlorite in that mill, which results in potential exposure to $\mathrm{Cl}$ gas, was stopped in 1998. $\mathrm{SO}_{2}$ and $\mathrm{ClO}_{2}$ are still used in Mill B, while Mill C ended use of these compounds in 1995. Workers in paper mills are not typically exposed to irritant gases.

The concentration of ozone in a pulp mill is low $(<40 \mathrm{ppb})$ under normal conditions, but can briefly be very high $(>10,000 \mathrm{ppb})$ during accidental gassings [15]. In 1995 and 1996 , stationary measurements of ambient ozone concentrations were conducted in Mills B and C for 366 days in two rooms that are critical areas for high ozone exposure. On 6 of the 366 days, ozone levels exceeded 900 ppb [15]. Stationary measurements probably were not representative of personal exposures during gassing events. Consequently, personal exposure to ozone gassings was based on each subject's selfreport during the follow-up survey in 1998-1999, and was defined as a positive response to the following question. "Have you been exposed to ozone with coughing, wheezing, breathlessness or pain in the chest as a result? If "yes," when did this occur?". Based on the subjects' recall to the second question, the year of the ozone gassing event was recorded to determine whether it occurred prior to, or during the interval period. A negative response for exposure to ozone gassing was assigned if the subject did not report the year in which the gassing event occurred. Similar pairs of questions from the baseline survey in 1995-1996 and the follow-up survey in 1998-1999 were used to identify participants with a history of exposure to $\mathrm{ClO}_{2}$ and $\mathrm{SO}_{2}$ gassings, to control for the effect of other irritant gassings while estimating the effect of ozone. Exposure to $\mathrm{ClO}_{2}$ and $\mathrm{SO}_{2}$ gassings were summarised into a single indicator variable that was positive if the person had experienced a gassing event due to either $\mathrm{ClO}_{2}$ or $\mathrm{SO}_{2}$. Irritant gassing exposure was summarised using the following categories: 1) Bleachery workers, reported gassings including ozone gassings (further divided by timing of gassings: pre-baseline survey and/or during the interval between baseline and follow-up surveys) and $\mathrm{ClO}_{2} /$ $\mathrm{SO}_{2}$ gassings. 2) Bleachery workers, no reported gassings. 3) Paper mill workers (no irritant gassings).

\section{Outcome assessment}

All of the subjects underwent baseline spirometry in 1995-1996 and follow-up spirometry in 1998-1999. The spirometry tests were administered by the same team of research nurses using the same equipment (dry-wedge spirometer; Vitalograph ${ }^{\circledR}$, Buckingham, UK) at baseline and at follow-up. Each subject performed at least three technically acceptable trials, and the largest values for FVC and FEV1 were retained and compared with predicted values [18]. Details of spirometry measurements are documented in previous studies [14, 15].

Each subject's average annual changes in FEV1 ( $\triangle \mathrm{FEV} 1), \mathrm{FVC}$ $(\Delta \mathrm{FVC})$, and $\mathrm{FEV} 1 / \mathrm{FVC}(\Delta \mathrm{FEV} 1 / \mathrm{FVC})$ were calculated using the following equation:

(Follow-up spirometry value) - (Baseline spirometry value) Years between baseline and follow-up tests

Chronic airflow limitation was defined as FEV1/FVC less than the lower limit of normal (LLN) at the follow-up survey [19]. A fixed $\mathrm{FEV} 1 / \mathrm{FVC}$ ratio (e.g. FEV1/FVC $<70 \%$ ) was used, as the LLN is not recommended in adults because FEV1/FVC is inversely related to age and height [19]. One statistically 
acceptable approach for establishing lower limits for any spirometric measure is to define the lowest $5 \%$ of the reference population as below the LLN [19]. For the current study, the FEV1/FVC value of the fifth percentile was estimated as:

$$
\mathrm{LLN}=\mathrm{FEV}_{1} / \mathrm{FVC} \text { predicted value }-(1.645 \times \mathrm{RSD})
$$

Where RSD is the residual standard deviation constant derived from reference population [18].

The reference population, from which the predicted values and numeric RSD constant are derived, consisted of healthy adult males and females from Sweden [18].

\section{Statistical analysis}

Univariate tests for statistical significance were accomplished using Fisher's exact test or a continuity-corrected Chi-squared test for categorical variables, and an unpaired t-test for continuous variables [20].

Using linear regression [21], baseline and follow-up FEV1, $\mathrm{FVC}$, and FEV1/FVC ratio, and $\triangle \mathrm{FEV} 1, \triangle \mathrm{FVC}$, and $\triangle \mathrm{FEV} 1 /$ FVC, were modelled as continuous outcomes against exposure class dummy variables controlling for potential confounders. The exposure class dummy variables represented the gassings that were reported to have occurred pre-baseline and during the interval, according to the outcome that was being modelled. Paper mill workers served as the reference group. Potential confounders included age, sex, average weight, average height, smoking status, and pack-yrs smoked, as well as baseline spirometry for the models of longitudinal change. The averages of weight and height as potential confounders were used to resolve minor differences between baseline and follow-up measurements. For subjects who were missing recorded weight values at baseline $(n=14)$, the single recorded weight value at follow-up was used instead of the average. Age and smoking variables were as of the baseline or followup survey for the models of cross-sectional spirometry. For longitudinal change in spirometry, age was the mean of baseline and follow-up ages, smoking status was during the interval, and pack-yrs smoked was the total at the end of the interval.

For chronic airflow limitation at follow-up, prevalence ratios were calculated to express the effect of occupational exposure. Prevalence ratios were chosen, rather than odds ratios, because they are more conservative and interpretable relative to incident rate ratios [22]. Since relatively few workers fulfilled the criteria for chronic airflow limitation, the number of potential confounders was limited by conducting forward and backward stepwise model fitting. The potential confounders were the same as those used in the linear regression models: age at follow-up, sex, average weight, average height, smoking status at follow-up, and pack-yrs smoked by follow-up. There were separate indicator variables for current and former smoking, but they were both retained in the model if one of them fulfilled the criteria for inclusion. The exposure variables were always in the model. Other covariates were included with a $p$-value $\leqslant 0.10$ and excluded if $p>0.20$. If a covariate had a $p$ value $0.10-0.20$, it was tested further by removing it from the model to see whether this caused a change of $\geqslant 15 \%$ in the effect estimates for the relevant exposure variables. If such a change was observed then it was kept in the model. The final models from forward and backward model fitting were compared and the model with more covariates was used.

\section{RESULTS}

Of the 232 participants included in the study, there were 54 paper mill workers with no exposure to irritant gassings $(23 \%)$ and 178 bleachery workers with potential exposure (77\%). The mean interval period (i.e. time between baseline and follow-up spirometry tests) for all participants was 3.4 yrs $(\mathrm{SD}=0.7)$. At follow-up, 124 bleachery workers reported irritant gassings, but only 61 bleachery workers reported gassings that occurred during the interval period. The sample sizes in the irritant gassing exposure classes at baseline and during the interval period are presented in tables 1 and 2, respectively. Of the 66 bleachery workers who had reported ozone gassings by follow-up, 31 reported only gassings that occurred prior to baseline, 16 reported only gassings that occurred after baseline, and 19 reported gassings that occurred during both periods.

The mean \pm SD age, average weight and average height for all participants were $43.7 \pm 8.6 \mathrm{yrs}, 83.3 \pm 11.6 \mathrm{~kg}$, and $178.0 \pm 7.4 \mathrm{~cm}$, respectively. There were no statistically significant $(\mathrm{p}<0.05)$ differences in these variables between the bleachery exposure classes (at baseline, during the interval, or at follow-up) and the paper mill workers. Mean pack-yrs smoked at baseline and follow-up for all participants were $6.2 \pm 9.5$ and $6.5 \pm 10.1$, respectively. Bleachery workers with ozone gassings both pre-baseline and during the interval had a

TABLE 1 Mean per cent predicted FEV1 and FVC, and mean FEV1/FVC ratio at baseline for all participants and by exposure status

\begin{tabular}{|c|c|c|c|c|}
\hline \multirow[t]{2}{*}{ Exposure categories ${ }^{\#}$} & \multirow[t]{2}{*}{ Subjects $\mathbf{n}^{\#}$} & \multicolumn{2}{|c|}{ Mean $\%$ predicted } & \multirow[t]{2}{*}{ Mean FEV $1 /$ FVC $\%$} \\
\hline & & FEV1 & FVC & \\
\hline Pre-baseline ozone gassings & 50 & $101.3 \pm 1.80$ & $97.7 \pm 1.58$ & $79.3 \pm 1.0$ \\
\hline Pre-baseline $\mathrm{ClO}_{2} / \mathrm{SO}_{2}$ gassings & 99 & $102.9 \pm 1.35$ & $98.3 \pm 1.22$ & $78.9 \pm 0.6$ \\
\hline Bleachery workers, no gassings & 67 & $103.1 \pm 1.37$ & $99.0 \pm 1.38$ & $80.4 \pm 0.7$ \\
\hline
\end{tabular}

Data presented as mean \pm SEM. FEV1: forced expiratory volume in one second; FVC: forced vital capacity. ${ }^{\#}: 38$ study participants reported ozone and chlorine dioxide $\left(\mathrm{ClO}_{2}\right)$ /sulphur dioxide $\left(\mathrm{SO}_{2}\right)$ gassings before the baseline survey. 


\begin{tabular}{|c|c|c|c|c|c|c|c|}
\hline & Subjects $n$ & Parameter & p-value & Parameter & p-value & Parameter & p-value \\
\hline Only pre-baseline ozone gassings & 31 & +22 & 0.054 & +25 & 0.10 & -0.05 & 0.81 \\
\hline $\mathrm{ClO}_{2} / \mathrm{SO}_{2}$ gassings ${ }^{+}$ & 107 & -24 & 0.01 & -19 & 0.11 & -0.15 & 0.35 \\
\hline Bleachery workers, no gassings & 54 & -9 & 0.37 & -20 & 0.14 & +0.15 & 0.42 \\
\hline
\end{tabular}

$\Delta \mathrm{FEV} 1$ : average annual change in forced expiratory volume in one second; $\Delta \mathrm{FVC}$ : average annual change in forced vital capacity (FVC). ${ }^{\#}$ : Adjusted for average age, sex, average weight, average height, smoking status during interval (i.e. current or former versus never), total pack-yrs smoked by end of interval, and baseline spirometry value; ": exposure categories had a common comparison group in the paper mill workers $(n=54)$. By follow-up, 49 study participants reported ozone and chlorine dioxide $\left(\mathrm{ClO}_{2}\right)$ /sulphur dioxide $\left(\mathrm{SO}_{2}\right)$ gassings; ${ }^{+}$: the " $\mathrm{ClO}_{2} / \mathrm{SO}_{2}$ gassings" variable accounted for both pre-baseline and interval gassings

lower mean pack-yrs at follow-up than paper mill workers $(\mathrm{p}<0.05)$.

Only $13 \%(n=31)$ of the participants were current smokers by follow-up; $37 \%(n=86)$ were former smokers. There were no statistically significant differences in current and former smoking between the bleachery exposure classes and paper mill workers. The participants were predominantly male $(\mathrm{n}=211 ; 91 \%)$; bleachery workers who reported $\mathrm{ClO}_{2} / \mathrm{SO}_{2}$ gassings pre-baseline or during the interval were less likely to be female in comparison with paper mill workers $(\mathrm{p}<0.05)$.

The mean \pm SD baseline spirometry values for all 232 participants were $4.13 \pm 0.7 \mathrm{~L} \mathrm{FEV1,} \mathrm{5.19} \pm 0.9 \mathrm{~L} \mathrm{FVC}$, and $79.6 \pm 5.9 \%$ FEV1/FVC. The mean per cent predicted FEV1 and FVC, and the mean FEV1/FVC ratio at baseline for all participants and by exposure status are presented in table 1 . The only prebaseline ozone gassings category had the lowest per cent predicted values. When regression models were fitted for FEV1 and FVC, with paper mill workers as the comparison group and variables included to control for confounding, none of the coefficients for exposure reached the level of statistical significance (i.e. $\mathrm{p} \leqslant 0.05$ ) (models not shown). The variable for pre-baseline ozone gassings attained borderline statistical significance in the regression model for FEV1 with a coefficient of $-139 \mathrm{~mL}(\mathrm{p}=0.098)$, but not in the model for FVC $(-128 \mathrm{~mL}$, $\mathrm{p}=0.20)$. The coefficients for pre-baseline $\mathrm{ClO}_{2} / \mathrm{SO}_{2}$ gassings from the same models were $+51 \mathrm{~mL}(\mathrm{p}=0.52)$ for FEV1 and $+57 \mathrm{~mL}(\mathrm{p}=0.55)$ for FVC. The mean values for the FEV1/FVC ratio varied little among the different exposure classes (table 1), and the same was observed in the regression model for this outcome (model not shown).

From the longitudinal regression models (table 2), declines of $-24 \mathrm{~mL} \cdot \mathrm{yr}^{-1} \mathrm{FEV} 1(\mathrm{p}=0.01)$ and $-19 \mathrm{~mL} \cdot \mathrm{yr}^{-1} \mathrm{FVC}(\mathrm{p}=0.11)$ were associated with $\mathrm{ClO}_{2} / \mathrm{SO}_{2}$ gassings (models $\mathrm{A}$ and $\mathrm{B}$ ). The 31 workers who reported ozone gassings by baseline, but not during the interval between baseline and follow-up, had positive coefficients of $+22 \mathrm{~mL} \cdot \mathrm{yr}^{-1}$ FEV1 $(\mathrm{p}=0.054)$ and $+25 \mathrm{~mL} \cdot \mathrm{yr}^{-1}$ FVC $(p=0.10)$. The workers who reported that ozone gassings occurred only during the interval had a positive coefficient of $+0.44 \% \cdot \mathrm{yr}^{-1}(\mathrm{p}=0.10)$ for $\mathrm{FEV} 1 / \mathrm{FVC}$ (model C, table 2). The rate of decline of FEV1/FVC was greatest for workers with both pre-baseline and interval ozone gassings $\left(-0.34 \% \cdot \mathrm{yr}^{-1}\right)$, although it was not statistically significant $(\mathrm{p}=0.19)$.

There were no statistically significant associations between spirometry at follow-up and gassing exposures after controlling for potential confounders (regression models not shown). The only finding of borderline statistical significance was for study participants with both pre-baseline and interval ozone gassings, with a coefficient of $-217 \mathrm{~mL} \mathrm{FEV1}(\mathrm{p}=0.095)$.

Nineteen workers were classified as having chronic airflow limitation at follow-up, or $8.2 \%$ of the 232 participants. They had a mean per cent predicted \pm SEM FEV1 at follow-up of $88.3 \pm 3.7 \%$. Only three of the 19 workers had FEV1 $<80 \%$ pred; therefore, most of these workers had borderline obstructive disease [18]. The distribution by exposure class of these 19 workers is presented in table 3 . The prevalence was lowest for paper mill workers $(3.7 \%)$ and highest for workers with only

\begin{tabular}{lcc}
\hline TABLE 3 & $\begin{array}{c}\text { Chronic airflow limitation at follow-up by exposure } \\
\text { class }\end{array}$ \\
\hline $\begin{array}{l}\text { Exposure classes } \\
\text { Distribution of workers } \\
\text { at follow-up }\end{array}$ & $\begin{array}{c}\text { Chronic airflow } \\
\text { limitation }\end{array}$ \\
\hline $\begin{array}{l}\text { Pre-baseline ozone gassings } \\
\text { Pre-baseline and interval ozone }\end{array}$ & 31 & $5(16.1)$ \\
gassings & 19 & $3(15.8)$ \\
Interval ozone gassings & 16 & $1(6.3)$ \\
ClO $\mathbf{S O}_{\mathbf{2}}$ gassings & 107 & $9(8.4)$ \\
$\begin{array}{l}\text { Bleachery workers, no gassings } \\
\text { Paper mill workers }\end{array}$ & 54 & $5(9.3)$ \\
Total & 54 & $2(3.7)$ \\
\hline
\end{tabular}

Data presented as $\mathrm{n}$ or $\mathrm{n}(\%)$. $\mathrm{ClO}_{2}$ : chlorine dioxide; $\mathrm{SO}_{2}$ : sulphur dioxide. ${ }^{\#}$ : Chronic airflow limitation was defined as forced expiratory volume in one second/forced vital capacity less than the lower limit of normal; " : by follow-up, 49 study participants reported both ozone and $\mathrm{ClO}_{2} / \mathrm{SO}_{2}$ gassings. 


\begin{tabular}{|c|c|c|c|c|}
\hline \multirow{2}{*}{$\begin{array}{l}\text { TABLE } 4 \\
\text { Variables }\end{array}$} & \multicolumn{4}{|c|}{$\begin{array}{l}\text { Regression model for chronic airflow limitation at } \\
\text { follow-up\# }\end{array}$} \\
\hline & & $\begin{array}{l}\text { Prevalence } \\
\text { ratio }\end{array}$ & $95 \% \mathrm{Cl}$ & p-value \\
\hline \multicolumn{2}{|c|}{ Only pre-baseline ozone gassings } & 4.3 & $1.2-15.7$ & 0.03 \\
\hline \multicolumn{2}{|c|}{$\begin{array}{l}\text { Both pre-baseline and interval } \\
\text { ozone gassings }\end{array}$} & 5.5 & $1.1-28.0$ & 0.04 \\
\hline \multicolumn{2}{|c|}{ Only interval ozone gassings } & 1.8 & $0.2-16.7$ & 0.59 \\
\hline \multicolumn{2}{|c|}{$\mathrm{ClO}_{2} / \mathrm{SO}_{2}$ gassings } & 0.8 & $0.2-2.8$ & 0.75 \\
\hline \multicolumn{2}{|c|}{ Bleachery workers, no gassings } & 1.7 & $0.4-6.5$ & 0.45 \\
\hline \multicolumn{2}{|l|}{ Female } & 3.4 & $1.1-9.8$ & 0.03 \\
\hline \multicolumn{2}{|c|}{ Current smoker $^{+}$} & 2.9 & $0.9-9.9$ & 0.08 \\
\hline \multicolumn{2}{|c|}{ Former smoker $^{+}$} & 1.5 & $0.5-4.3$ & 0.46 \\
\hline \multicolumn{5}{|c|}{$\begin{array}{l}\mathrm{Cl} \text { : confidence interval; } \mathrm{ClO}_{2} \text { : chlorine dioxide; } \mathrm{SO}_{2} \text { : sulphur dioxide. }{ }^{\#} \text { : Chronic } \\
\text { aiflow limitation was defined as forced expiratory volume in one second/forced } \\
\text { vital capacity less than the lower limit of normal; }{ }^{\circledR} \text { : work-related exposure } \\
\text { classes have a common comparison group in the paper mill workers; }{ }^{+} \text {: } \\
\text { smoking status was at follow-up. }\end{array}$} \\
\hline
\end{tabular}

pre-baseline ozone gassings (16.1\%) and both pre-baseline and interval ozone gassings $(15.8 \%)$. In the regression model for chronic airflow limitation (table 4), these two ozone gassing categories had elevated prevalence ratios of 4.3 (95\% confidence interval (CI) 1.2-15.7) and 5.5 (95\% CI 1.1-28.0), respectively. There was no evidence of interaction between these variables for ozone gassings and the variables for potential confounders in the model. None of the other gassing variables, including the one for only interval ozone gassings, had a prevalence ratio that was elevated and statistically significant. Thus, the pre-baseline exposures, but not the interval exposures, appeared to be responsible for the relationship between ozone gassings and chronic airflow limitation.

\section{DISCUSSION}

In the current study, bleachery workers who reported only prebaseline ozone gassings or a combination of pre-baseline and interval ozone gassings were more likely to have chronic airflow limitation at follow-up than nongassed paper mill workers. Although most of the study participants classified with chronic airflow limitation had borderline obstructive disease, they might be at risk for subsequent adverse outcomes. In particular, a recent analysis of the first National Health and Nutrition Examination Survey (NHANES I) population found that mild chronic obstructive pulmonary disease (COPD) (FEV1/FVC $<70 \%$ and $\mathrm{FEV} 1 \geqslant 80 \%$ pred) was associated with excess mortality [23].

From the regression models for the baseline survey, the bleachery workers who reported ozone gassings tended to have lower values for FEV1, but this was not observed for their co-workers who had reported gassings due to $\mathrm{ClO}_{2} / \mathrm{SO}_{2}$. This difference at baseline could have been the result of unmeasured differences in the levels of exposure that occurred during gassing events. Specifically, it is likely that high exposures accompanied the onset of ozone use prior to the baseline survey. When Mills B and C began to use ozone in the 1990s, they were not prepared for its strong corrosive properties, which led to numerous leaks and pipe breaks [6]. In at least one of the two mills, the workers identified as most exposed to ozone developed chronic bronchiolitis [16]. Also, the workers who had suffered the adverse effects of $\mathrm{ClO}_{2} / \mathrm{SO}_{2}$ gassings might have left the work force over the years and not have been available for testing (i.e. selection bias). Ozone had been used for a relatively short period of time, and there might have been less loss of workers affected by ozone peak exposures.

The absence of substantial longitudinal declines in FEV1 and FVC associated with post-baseline ozone gassings might reflect improvements in the control of ozone exposure during the interval. In contrast, bleachery workers who reported pre- or post-baseline $\mathrm{ClO}_{2}$ or $\mathrm{SO}_{2}$ gassings experienced declines in FEV1 and FVC during the interval period. When $\triangle F E V 1$ and $\triangle \mathrm{FVC}$ were modelled with $\mathrm{ClO}_{2}$ and $\mathrm{SO}_{2}$ gassings represented by separate variables, elevated declines in FEV1 and FVC in comparison with paper mill workers were seen mainly in bleachery workers who reported $\mathrm{ClO}_{2}$ gassings (data not shown).

As described in the Introduction, previous cross-sectional studies based on subsets of the current cohort did not consistently find an association between lower pulmonary function and bleachery work or ozone gassings [14-16]. Other cross-sectional studies on pulp mill workers have found an association between airflow obstruction and gassings to $\mathrm{Cl}$ or $\mathrm{ClO}_{2}[2,4-5]$. Further cross-sectional studies have observed concurrent decrements in FEV1 and FVC in workers exposed to $\mathrm{SO}_{2}$ or $\mathrm{Cl}$ gases $[3,24,25]$ or to acetic acid [26]. The concurrent decrements might reflect hyperinflation with an increased residual volume and, thus, not be indicative of a true restrictive disorder. Industry-based epidemiological studies have also shown that occupational exposure to inorganic and organic dusts and to chemical agents can cause COPD [27-29].

Respiratory health effects due to occupational exposure to ozone have been reported for other occupational groups, including welders and outdoor workers [30-34]. Welders, who in certain processes are exposed to high levels of ozone and nitrogen oxide, have been reported to have lower pulmonary function and higher prevalence of work-related respiratory symptoms than nonwelders [31, 32], but one longitudinal study reported no association between ozone exposure and accelerated decline in lung function [30]. From a communitybased cross-sectional survey, participants (both smokers and nonsmokers) with high ambient exposures to photochemical oxidants were more likely to have FEV1 and FVC $<50 \%$ pred compared with participants with low ambient exposures [12]. However, when the investigators retested a subset of this cohort, nonsmoking adults with elevated ambient ozone exposures did not have an accelerated longitudinal decline in FEV1 or FVC over an 8-10-yr period [13].

Some features of the current study design may have minimised the ability to detect a significant ozone exposure-related longitudinal change in lung function. While the exposure history for ozone included the period beginning from onset of ozone use in the pulp mills during the early-to-mid-1990s up to the follow-up survey in 1998-1999, spirometry testing of the workers began in 1995-1996. Unfortunately, spirometry data for study participants at the start of ozone use is not available, 
with the exception of Mill A. When similar longitudinal analyses comparing pulp mill workers in Mill A with paper mill workers from Mills B and C were ran, the effect of ozone gassings was no more than when all pulp mill workers were included (data not shown). The follow-up spirometry values should reflect all work-related effects up to that point and, therefore, are the most appropriate outcomes when examining the effect of ozone gassings since onset of use.

Based on the work of other researchers, the current study may have needed more subjects and additional serial pulmonary function testing to observe a significant work-related effect for ozone over a 3-4-yr period [35]. While paper mill workers, selected as the internal control group, did not experience gassing events, they were exposed to paper dust, which has been previously shown to be associated with lower respiratory symptoms and impaired lung function $[1,36]$. Thus, the ability to detect an effect of gassings may have been reduced.

A loss to follow-up can bias findings towards the null in any longitudinal study. This may have occurred in the current study if bleachery workers who developed respiratory problems during the study period had left the pulp mill and were therefore not included in the study. However, there was little opportunity for this problem because only four of the bleachery workers tested in 1996 did not complete testing in 1999. Recall bias can also occur in studies that derive exposure data by questionnaires if recall of those data varies by disease status. It might have occurred in the current study if bleachery workers with more severe lung function abnormalities were more likely to recall irritant gassing incidents. A gassing event was counted if the worker experienced acute respiratory symptoms. Someone who had acute respiratory symptoms after a high-exposure event might have been more susceptible than a co-worker who had the same exposure but did not have symptoms. Since $70 \%$ of the bleachery workers reported being gassed by ozone and/or $\mathrm{ClO}_{2} / \mathrm{SO}_{2}$, it seems that they included many more people than the subset of the study population that was susceptible. Still, those susceptible to irritant gassings might have been over-represented in the gassed group, which could have biased the effect estimates away from the null.

In conclusion, bleachery workers who reported either pre- or post-baseline chlorine dioxide/sulphur dioxide gassings were at elevated risk for declines in forced expiratory volume in one second and forced vital capacity during the interval between baseline and follow-up. While ozone gassings were not associated with a rapid decline in pulmonary function during the study period, bleachery workers who reported ozone gassings prior to the study period were more likely to have chronic airflow limitation at follow-up. The findings suggest that obstructive effects among pulp mill workers are associated with ozone gassings, and that adverse effects on spirometry might also accompany chlorine dioxide/sulphur dioxide gassings. Peak exposures to irritant gases in pulp mills should be prevented.

\section{REFERENCES}

1 Torén K, Hagberg S, Westberg H. Health effects of working in pulp and paper mills: exposure, obstructive airways diseases, hypersensitivity reactions, and cardiovascular diseases. Am J Ind Med 1996; 29: 111-122.

2 Kennedy SM, Enarson DA, Janssen RG, Chan-Yeung M. Lung health consequences of reported accidental chlorine gas exposures among pulp mill workers. Am Rev Respir Dis 1991; 143: 74-79.

3 Henneberger PK, Eisen EA, Ferris BG. Pulmonary function among pulp and paper workers in Berlin, New Hampshire. Br J Ind Med 1989; 46: 765-772.

4 Henneberger PK, Ferris BG, Sheehe PR. Accidental gassing incidents and the pulmonary function of pulp mill workers. Am Rev Respir Dis 1993; 148: 63-67.

5 Henneberger PK, Lax MB, Ferris BG. Decrements in spirometry values associated with chlorine gassing events and pulp mill work. Am J Respir Crit Care Med 1996; 153: 225-231.

6 Torén K, Blanc PD. The history of pulp and paper bleaching: respiratory health effects. Lancet 1997; 349: 1316-1318.

7 Krishna MT, Mudway I, Kelly FJ, Frew AJ, Holgate ST. Ozone, airways, and allergic airways disease. Clin Exp Allergy 1995; 25: 1150-1158.

8 McDonnell WF, Stewart PW, Andreoni S, et al. Prediction of ozone-induced FEV1 changes: effects of concentration, duration, and ventilation. Am J Respir Crit Care Med 1997; 156: 715-722.

9 McDonnell WF, Stewart PW, Smith MV, Pan WK, Pan J. Ozone-induced respiratory symptoms: exposure-response models and association with lung function. Eur Respir J 1999; 14: 845-853.

10 Abbey DE, Petersen F, Mills PK, Beeson WL. Long-term ambient concentrations of total suspended particulates, ozone, and sulphur dioxide and respiratory symptoms in a nonsmoking population. Arch Environ Health 1993; 48: 33-46.

11 McDonnell WF, Abbey DE, Nishino N, Lebowitz MD. Long-term ambient ozone concentration and the incidence of asthma in nonsmoking adults: the AHSMOG study. Environ Res 1999; 80: 110-121.

12 Detels R, Sayre JW, Coulson AH, et al. The UCLA population studies of chronic obstructive respiratory disease. IV. Respiratory effect of long-term exposure to photochemical oxidants, nitrogen dioxide, and sulphates on current and never smokers. Am Rev Respir Dis 1981; 124: 673-680.

13 Gong HJ, Simmons MS, Linn WS, McDonnell WF, Westerdahl D. Relationship between acute ozone responsiveness and chronic loss of lung function in residents of a high-ozone community. Arch Environ Health 1998; 53: 313-319.

14 Olin AC, Ljungkvist G, Bake B, Hagberg S, Henriksson L, Torén K. Exhaled nitric oxide among pulpmill workers reporting gassing incidents involving ozone and chlorine dioxide. Eur Respir J 1999; 14: 828-831.

15 Olin AC, Granung G, Hagberg S, et al. Respiratory health among bleachery workers exposed to ozone and chlorine dioxide. Scand J Work Environ Health 2002; 28: 117-123.

16 Olin AC, Andersson E, Andersson M, Granung G, Hagberg S, Torén K. Prevalence of asthma and exhaled nitric oxide are increased in bleachery workers exposed to ozone. Eur Respir J 2004; 23: 87-92. 
17 Andersson E, Olin AC, Hagberg S, Nilsson R, Nilsson T, Torén K. Adult-onset asthma and wheeze among irritantexposed bleachery workers. Am J Ind Med 2003; 43: 532-538.

18 Berglund E, Birath G, Bjure J, et al. Spirometric studies in normal subjects: forced expirograms in subjects between 7 and 70 years of age. Acta Med Scand 1963; 173: 185-191.

19 American Thoracic Society. Lung function testing: selection of reference values and interpretative strategies. Am Rev Respir Dis 1991; 144: 1202-1218.

20 Daniel W. Biostatistics: A Foundation for Analysis in the Health Sciences. 7th Edn. New York, John Wiley and Sons, 1999.

21 Kleinbaum DG, Kupper LL, Muller KE, Nizam A. Applied regression analysis and other multivariable methods. 3rd Edn. Pacific Grove, Duxbury Press, 1998.

22 Thompson ML, Myers JE, Kriebel D. Prevalence odds ratio or prevalence ratio in the analysis of cross sectional data: what is to be done? Occup Environ Med 1998; 55: 272-277.

23 Mannino DM, Buist AS, Petty TL, Enright PL, Redd SC. Lung function and mortality in the United States: data from the First National Health and Nutrition Examination Survey follow up study. Thorax 2003; 58: 388-393.

24 Gautrin D, Leroyer L'archeveque J, Dufour JG, Girard D, Malo JL. Cross-sectional assessment of workers with repeated exposure to chlorine over a three year period. Eur Respir J 1995; 8: 2046-2054.

25 Chang-Yeung M, Lam S, Kennedy SM, Frew AJ. Persistent asthma after repeated exposure to high concentrations of gases in pulpmills. Am J Respir Crit Care Med 1994; 149: 1676-1680.

26 Rajan KG, Davies BH. Reversible airways obstruction and interstitial pneumonitis due to acetic acid. $\mathrm{Br} J$ Ind Med 1989; 46: 67-68.
27 Becklake M. Occupational exposures: evidence for a causal association with chronic obstructive pulmonary disease. Am Rev Respir Dis 1989; 140, Suppl. 3: S85-S91.

28 Oxman AD, Muir DCF, Shannon HS, Stock SR, Hnizdo E, Lange HJ. Occupational dust exposure and chronic obstructive pulmonary disease. A systematic overview of the evidence. Am Rev Respir Dis 1993; 148: 38-48.

29 Kauffmann F, Drouet D, Lellouch J, Brille D. Occupational exposure and 12 year spirometric changes among Paris area workers. Br J Ind Med 1982; 39: 221-232.

30 Beckett WS, Pace PE, Sferlazza SJ, Perlman GD, Chen AH, $\mathrm{Xu}$ XP. Airway reactivity in welders: a controlled prospective cohort study. J Occup Environ Med 1996; 38: 1229-1238.

31 Donoghue AM, Glass WI, Herbison GP. Transient changes in the pulmonary function of welders: a cross sectional study of Monday peak expiratory flow. Occup Environ Med 1994; 51: 553-556.

32 Bradshaw LM, Fishwick D, Slater T, Pearce N. Chronic bronchitis, work related respiratory symptoms, and pulmonary function in welders in New Zealand. Occup Environ Med 1998; 55: 150-154.

33 Brauer M, Blair J, Vedal S. Effect of ambient ozone exposure on lung function in farm workers. Am J Respir Crit Care Med 1996; 154: 981-987.

34 O'Neill MS, Geyh AS, Sienra-Monge JJ, Romieu I. Ozone exposure among Mexico City outdoor workers. J Air Waste Manage Assoc 2003; 53: 339-346.

35 Wang ML, Gunel E, Petsonk EL. Design strategies for longitudinal spirometry studies: study duration and measurement frequency. Am J Respir Crit Care Med 2000; 162: 2134-2138.

36 Torén K, Jarvholm B, Sallsten Thiringer G. Respiratory symptoms and asthma among workers exposed to paper dust: a cohort study. Am J Ind Med 1994; 26: 489-496. 